\title{
ASSESSMENT OF COMPLICATIONS IN PATIENTS MALTREATED WITH FIXED SELF CURE ACRYLIC DENTURES.
}

1. BDS, FCPS

Senior Registrar

Department of Prosthodontics

Shahida Islam Medical and Dental

College Lodhran.

2. BDS, FCPS

Assistant Professor

Department of Prosthodontics

Bibi Aseefa Dental College, Larkana.

3. BDS, FCPS

Associate Professor

Department of Oral Maxillofacial

Surgery

Bibi Aseefa Dental College, Larkana.

4. BDS, FCPS

Associate Professor

Department of Oral Maxillofacial

Surgery

Bibi Aseefa Dental College, Larkana

5. BDS, FCPS

Assistant Professor

Department of Prosthodontics

Dow International Dental College,

Dow University of Health Sciences, Karachi Pakistan.

6. BDS, FCPS

Assistant Professor

Department of Prosthodontics

Dow University of Health Sciences

Karachi.

\section{Correspondence Address:}

Dr. Maimuna Khokhar

House Number 729, Sector C,

Askari X, Lahore Cantt.

memona_khokhar@yahoo.com

Article received on:

16/05/2019

Accepted for publication:

20/08/2019
Maimuna Khokhar ${ }^{1}$, Shabir Ahmed ${ }^{2}$, Muhammad Ilyas Shaikh ${ }^{3}$, Safia Shaikh ${ }^{4}$, Bharat Kumar ${ }^{5}$, Muneeb Ahmed Lone ${ }^{6}$

ABSTRACT... Objectives: The objective of this study is to assess the reasons which persuade patients to receive fixed self-cured acrylic dentures (FSD), their most common presenting complaints and the prevalence of complications (clinical and prosthesis-related) subsequent to maltreatment with FSD. Study Design: Descriptive cross-sectional study. Setting: Prosthodontics Department of Bibi Aseefa Dental College, Larkana. Period: $1^{\text {st }}$ January 2018 to $31^{\text {st }}$ December 2018. Material \& Methods: Using a structured proforma, data related to 75 patients, all maltreated with Fixed self-cure acrylic dentures (FSD) was collected. The condition of underlying mucosal tissues and abutment teeth was carefully assessed and recorded after removal of FSD. Evaluation of FSD prosthesis was also carried out. Results: $53.3 \%$ of patients reported lack of awareness as a reason for opting FSD with $28 \%$ patients presenting with pain as their main complaint. Clinical complications observed were poor oral hygiene (68\%), burning mouth sensations (58 \%), Halitosis $(77.3 \%)$, mobile $(64 \%)$ and carious $(46 \%)$ abutments, mucosal inflammation $(58.7 \%)$, and ulcerations $(30.7 \%)$. Prosthesis related complications included poor denture hygiene $(77.3 \%)$ tooth wear $(46.7 \%)$, prosthesis fracture $(37.3 \%)$ and discoloration (82.7\%). Conclusion: According to this study, it was observed that patients' lack of awareness was the main reason for opting FSD. The most common presenting complaint was pain, followed by poor esthetics. The prevalent clinical complications included poor oral hygiene, halitosis, burning mouth together with inflamed and ulcerative mucosa and, mobile and carious abutments. Prosthesis related complications included poor denture hygiene, wore out and fractured prosthesis with discoloration. An awareness on the complications of such maltreatment among patients is required to be created in order to discourage this malpractice.

Key words: $\quad$ Auto-polymerizing Acrylic Resins, Complications of FSD, Fixed Self-cure Acrylic Dentures, Maltreatment, Quackery.

Article Citation: Khokhar M, Ahmed S, Shaikh MI, Shaikh S, Kumar B, Lone MA. Assessment of Complications in patients Maltreated with fixed self-cure Acrylic Dentures. Professional Med J 2020; 27(1):125-131. DOI: 10.29309/TPMJ/2020.27.1.3724

\section{INTRODUCTION}

In the field of dentistry, there is wide use of acrylic resins since 1960's. ${ }^{1}$ The reason behind the wide application of these polymeric materials is due to their easy availability, low cost, and acceptable biological, physical and mechanical properties. ${ }^{2}$ Although far from ideal, these acrylic resins are most widely used for fabrication of complete and partial denture bases, artificial teeth, provisional crowns, relining and repair purposes, oral removable splints, obturator prosthesis, removable orthodontic appliances etc. ${ }^{3}$ On basis of the mode of activation, they are further classified into heat activated, auto polymerized / chemical activated / self-cured, light activated, thermoplastic type resins and microwave cured acrylic resins. ${ }^{4}$ Regardless of the mode of activation, these acrylic resins consist of a polymethylmethacrylate powder and methyl methacrylate liquid. Residual methyl methacrylate monomer (residual MMA) is among the most common documented allergens ${ }^{3}$, causing contact stomatitis, cheilitis, burning sensations and mouth soreness in patients ${ }^{5}$, along with skin / eye irritation and contact dermatitis in dental personnel who are subject to frequent material handling. ${ }^{6}$ Due to incomplete polymerization, the amount of residual MMA in the auto polymerized acrylic resins is much higher as compared to other types of acrylic resins. ${ }^{7}$ Over an extended period, this residual monomer starts leaking out in the oral environment due to its small size, 
hydrophilic nature and easy penetration in oral mucosa, resultantly causing adverse reactions. ${ }^{8,9}$

These acrylic resins have their valid uses. Nevertheless, an inherent potential of misuse of the self-cured acrylic resins exists due to its easy availability and low cost. ${ }^{10}$ This is manifested in form of malpractices carried out by unqualified quacks, generally prevalent in poor socioeconomic population. ${ }^{11}$ Often patients presenting with missing teeth are reluctant to opt for removable prosthesis, and instead want a fixed prosthesis even where not recommended. The valid fixed options such as porcelain fused to metal bridges, implant supported crown / bridges etc are expensive. ${ }^{12}$ Due to financial constraints and insistence of fixed prosthesis, patients then look for other low-cost alternatives. Unfortunately, quacks capitalize in such scenarios and offer fixed self-cured acrylic denture (FSD) as low-cost quick alternative to a fixed prosthesis. ${ }^{13}$ Fixed selfcure acrylic dentures (FSD) is the malpractice of using self-cured/auto-polymerized acrylic resin for fixing the missing teeth directly in the oral cavity, often in conjunction with stainless steel wires on abutment teeth. ${ }^{14}$ The auto-polymerized acrylic base is extended onto anterior and posterior saddle area of the ridge and fixed onto the ridge with auto polymerizing acrylic resin., thus making it almost impossible to maintain oral and denture hygiene. ${ }^{15}$ These unstable, ill-fitted and poorly designed FSDs further aggravate the undesirable effects of self-cured acrylic resins including but not limited to, mucosal redness, inflammation, swelling, ulcerations, gingivitis, gingival recession, periodontitis, teeth mobility, secondary caries, halitosis, burning mouth, epulis fissuratum, fibromas, poor esthetics, inefficient mastication etc. ${ }^{16,17}$

The literature review shows that few studies had already been conducted which demonstrated the adverse effects of fixed self-cure acrylic dentures. ${ }^{18}$ These studies concluded that use of FSD can lead to permanent mucosal damage as well as alveolar bone resorption, particularly around abutment teeth. ${ }^{19}$ However, these studies remained elusive primarily because of limited sample size, duration of FSD usage spectrum and restricted demographic distribution. ${ }^{20}$ Other clinical complications including carious and mobile abutments, gingival reactions, mucosal ulcerations and inflammation were not studied on statistically significant basis. Data available regarding prosthesis-related complications was also very limited. ${ }^{21,22}$

In order to address the issue on a comprehensive level, a large number of patients maltreated with fixed self-cured acrylic dentures are included in this study. $=23$ These patients belong to interior Sindh area having a low literacy rate, poor socioeconomic conditions and a prevalent quack culture. The authors of this study are of the opinion that the study settings are therefore ideal for providing a significantly larger sample size. ${ }^{24}$ Rationale of this study is to assess reasons motivating patients to opt for FSDs and occurrence of complications caused by use of fixed self-cure dentures. Therefore, an awareness on the complications of such maltreatment among patients can be created in order to discourage this malpractice. The objective of this study is to assess the reasons which persuade patients to receive fixed self-cured acrylic dentures (FSD), their most common presenting complaints and the prevalence of complications (clinical and prosthesis-related) subsequent to maltreatment with FSD in Larkana and its periphery population.

\section{MATERIAL AND METHODS}

This descriptive study with a convenient sampling technique was carried out from January 2018 to December 2018 at Prosthodontics Department of Bibi Aseefa Dental College, Larkana. Using a structured proforma, data related to 75 patients, all wearing fixed self-cured acrylic dentures (FSD) was collected. After an informed consent, the proforma was filled for socio-demographic details, practitioner qualification, reasons for receiving FSD, duration of use and presenting complaints. Location of FSD in the arch was also noted. After a detailed history, a comprehensive intraoral clinical examination was done. With patient's consent, FSD was removed using a slow speed (Air Motor) hand piece and wire cutters, without jeopardizing health of oral tissues. After removal of the FSD, the condition of underlying 
mucosal tissues and abutment teeth was carefully assessed and recorded. Evaluation of FSD prosthesis was also carried out. The patients were educated about the consequences of this type of maltreatment. These patients were then treated with correct prosthodontic approach, keeping in mind the patient's financial status. The data was entered and statistically analyzed using SPSS version 24.

\section{RESULTS}

Of the total 75 patients examined, 34.7\% fell between the age group of 20-30 years. (Table-I) The females (57.3\%) outnumbered the males (42.7\%) (Figure-1). Most of the patients maltreated with fixed self-cure acrylic dentures (FSD) belonged to poor socioeconomic status (64\%) (Figure-2). Majority of the FSD were placed by quacks (84\%). (Figure-3)

Majority of patients $(34.7 \%)$ reported the duration of use of FSD equal to or less than one year (Figure-4). Main presenting complaint at the time of hospital visit was pain (28\%) followed by poor esthetics (21.3\%) and tooth mobility (17.3\%) (Table-II). $53.3 \%$ patients reported lack of awareness as a reason for opting FSD, followed by $24 \%$ opting due to financial constraints whereas $17.3 \%$ gave unwillingness for extractions of BDRs as a reason for choosing FSD (Table-III). It was observed that maximum number of patients had prosthesis in maxillary arch (53.3\%) with majority FSD being placed in anterior region (48\%) (TableIV). On clinical examination it was observed that $68 \%$ patients were having poor oral hygiene, $58 \%$ patients complained of burning mouth sensations while halitosis was present in $77.3 \%$ patients. After removal of the prosthesis, condition of abutment teeth was evaluated. It was observed that $40 \%$ patients had mobile abutments, $18.7 \%$ had carious abutment teeth while $24 \%$ patients had both mobile and carious abutments. The condition of mucosa beneath the prosthesis was examined which revealed inflammation in 58.7 $\%$ patients while $30.7 \%$ patients had ulcerative mucosa along with inflammation. Subsequent to clinal examination, evaluation of FSD prosthesis revealed that $77.3 \%$ patients were having poor denture hygiene. $46.7 \%$ patients had worn out prosthesis. In addition to wear, $37.3 \%$ patients also presented with prosthesis fracture. Discoloration of prothesis was observed in 82.7 $\%$ patients (Table-V).

\begin{tabular}{|c|c|c|}
\hline \multicolumn{3}{|c|}{ Age Distribution of Patients } \\
\hline Sr.No & Age Group & Percentage (\%) \\
\hline 1 & $20-30$ yrs. & 34.7 \\
\hline 2 & $31-40$ yrs. & 26.7 \\
\hline 3 & $41-50$ yrs. & 22.7 \\
\hline 4 & $51-60$ yrs. & 16 \\
\hline
\end{tabular}

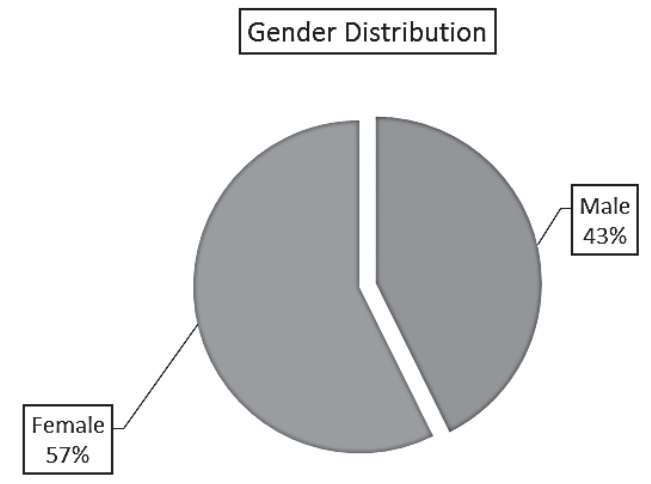

Figuare-1. Gender distribution of patients

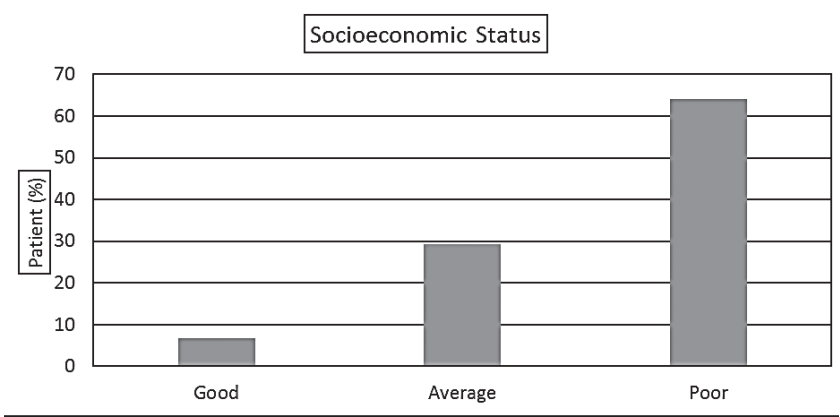

Figure-2. Socioeconomic status of patients

Practitioner Qualification

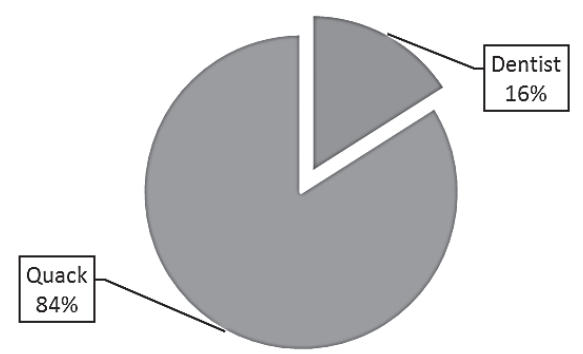

Figure-3. Practitioner qualification 


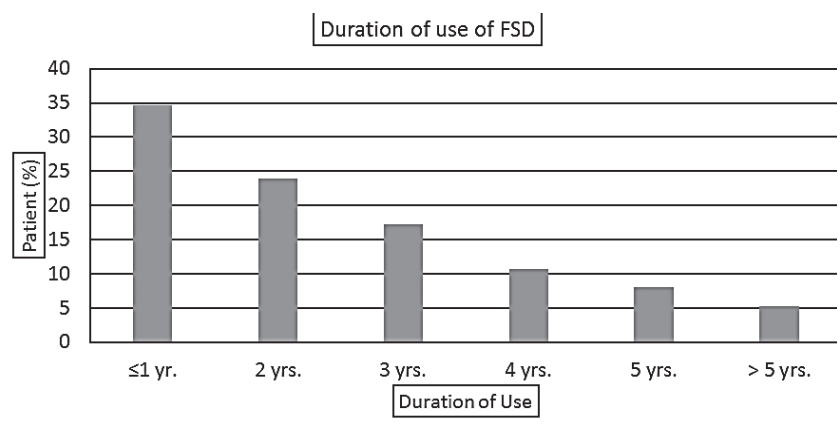

Figuare-4. Duration of use of FSD

\begin{tabular}{|c|c|c|c|c|}
\hline \multicolumn{5}{|c|}{ Presenting Complaints } \\
\hline Sr.No & \multicolumn{2}{|c|}{ Complaint } & \multicolumn{2}{|c|}{ Percentage (\%) } \\
\hline 1 & \multicolumn{2}{|r|}{ Pain } & \multicolumn{2}{|r|}{28} \\
\hline 2 & \multicolumn{2}{|c|}{ Poor Esthetics } & \multicolumn{2}{|r|}{21.3} \\
\hline 3 & \multicolumn{2}{|c|}{ Tooth Mobility } & \multicolumn{2}{|r|}{16.3} \\
\hline 4 & \multicolumn{2}{|c|}{ Difficulty in Chewing } & \multicolumn{2}{|r|}{13.7} \\
\hline 5 & \multicolumn{2}{|c|}{ Loose Denture } & \multicolumn{2}{|r|}{11.7} \\
\hline 6 & \multicolumn{2}{|c|}{ Bleeding Gums } & \multicolumn{2}{|r|}{ ? } \\
\hline \multicolumn{5}{|c|}{ Table-II. Presenting complaints of patients } \\
\hline \multicolumn{5}{|c|}{ Reasons for Opting FSD } \\
\hline Sr.No & \multicolumn{3}{|c|}{ Reason } & Percen \\
\hline 1 & \multicolumn{3}{|c|}{ Lack of Awareness } & 53.3 \\
\hline 2 & \multicolumn{3}{|c|}{ Poor Financial Status } & 24 \\
\hline 3 & \multicolumn{3}{|c|}{ Unwilling for BDR Extractions } & 17.3 \\
\hline 4 & \multicolumn{3}{|c|}{ Time Constraint } & 5.3 \\
\hline \multicolumn{5}{|c|}{ Table-III. Reasons for opting FSD } \\
\hline \multicolumn{5}{|c|}{$\begin{array}{l}\text { Distribution of FSD according to Arch and Site in } \\
\text { Arch }\end{array}$} \\
\hline \multicolumn{2}{|c|}{ Arch } & Percent(\%) & Site & Percent(\%) \\
\hline \multicolumn{2}{|c|}{ Maxillary } & 53.3 & Anterior & 48 \\
\hline \multicolumn{2}{|c|}{ Mandibular } & 26.7 & Posterior & 22.7 \\
\hline \multicolumn{2}{|c|}{$\begin{array}{l}\text { Max+Mand } \\
\text { (Both) }\end{array}$} & 20 & $\begin{array}{l}\text { Ant }+ \text { Post } \\
\text { (both) }\end{array}$ & 29.3 \\
\hline \multicolumn{5}{|c|}{$\begin{array}{l}\text { Table-IV. Distribution of FSD according to Arch and } \\
\text { Site in Arch }\end{array}$} \\
\hline
\end{tabular}

\section{DISCUSSION}

According to this study, $34.7 \%$ of patients maltreated with FSD are young adults in mean age group of $20-30$ yrs. Out of total patients presented, $57.3 \%$ are females. Most of patients are uneducated with limited financial resources that fell prey to maltreatment. This malpractice of providing fixed self-cure acrylic dentures was mostly carried out by quacks in poor socioeconomic population. The FSD had adversely affected the oral tissues compelling the patients to visit the qualified dentists for proper treatment of their problems.

\begin{tabular}{|c|c|c|c|}
\hline Sr.No & Parameter & Status & $\begin{array}{c}\text { Percent } \\
(\%)\end{array}$ \\
\hline \multicolumn{4}{|c|}{ Clinical Examination } \\
\hline \multirow{3}{*}{1} & \multirow{3}{*}{ Oral hygiene } & Excellent & 2.7 \\
\hline & & Good & 29.3 \\
\hline & & Poor & 68 \\
\hline \multirow{2}{*}{2} & \multirow{2}{*}{ Burning Mouth } & Present & 56 \\
\hline & & Absent & 44 \\
\hline \multirow{2}{*}{3} & \multirow{2}{*}{ Halitosis } & Present & 77.3 \\
\hline & & Absent & 22.7 \\
\hline \multicolumn{4}{|c|}{ Clinical Examination after Removal of Prosthesis } \\
\hline \multirow{4}{*}{4} & \multirow{4}{*}{$\begin{array}{l}\text { Condition of } \\
\text { Abutments }\end{array}$} & Healthy & 17.3 \\
\hline & & Mobile & 40 \\
\hline & & Carious & 18.7 \\
\hline & & Mobile \& Carious & 24 \\
\hline \multirow{3}{*}{5} & \multirow{3}{*}{$\begin{array}{l}\text { Condition of } \\
\text { Mucosa }\end{array}$} & Healthy & 10.6 \\
\hline & & Inflamed & 58.7 \\
\hline & & Ulcerative & 30.7 \\
\hline \multicolumn{4}{|c|}{ Evaluation of the Prosthesis (FSD) } \\
\hline \multirow{3}{*}{6} & \multirow{3}{*}{$\begin{array}{l}\text { Denture } \\
\text { Hygiene }\end{array}$} & Excellent & 2.7 \\
\hline & & Good & 24 \\
\hline & & Poor & 73.3 \\
\hline \multirow{3}{*}{7} & \multirow{3}{*}{$\begin{array}{l}\text { Condition of } \\
\text { Prosthesis }\end{array}$} & Good & 16 \\
\hline & & Wear out & 46.7 \\
\hline & & Fractured & 37.3 \\
\hline \multirow{2}{*}{8} & \multirow{2}{*}{$\begin{array}{l}\text { Discolouration } \\
\text { of Prosthesis }\end{array}$} & Present & 82.7 \\
\hline & & Absent & 17.3 \\
\hline & $\begin{array}{l}\text { Assessment } \\
\text { relatec }\end{array}$ & $\begin{array}{l}\text { clinical and proth } \\
\text { omplications }\end{array}$ & (FSD) \\
\hline
\end{tabular}

Although quacks were mostly responsible for this malpractice however $16 \%$ patients reported to have gotten their treatment from qualified dentists which is an alarming finding.

Complications can both be short term and long term depending on duration of use of FSD. According to this study, $34.7 \%$ patients presented with in a year of denture usage with complications. $28 \%$ patients presented with complaints of pain while $21.3 \%$ patients complained of poor esthetics. Complaints of bleeding gums, inefficient mastication, tooth mobility and loose 
dentures were also reported.

Lack of knowledge and awareness in the population was cited as the most common reason $(53.3 \%)$ together with financial and time constraints along with unwillingness to remove BDrds further pushing patients to opt for such maltreatments. Since most FSD were found to be replacing anterior teeth in upper arch so esthetics is also a major issue that lead patients to opt for quick cheap replacements.

Patients had poor oral hygiene with burning sensations and halitosis. $89.4 \%$ patients were observed to have inflamed and ulcerative mucosa with redness, swelling and soreness primarily due to an inability of patient to clean the underlying area beneath the denture. The mucosal health was further deteriorated due to leaching of unreacted monomer from the self-cure resin base.

The abutment teeth were in poor condition with $82.4 \%$ of them either mobile, carious or both. Due to poor hygiene maintenance and use of stainless-steel wires on abutment teeth $42.7 \%$ abutment teeth had carious cavities. Majority of abutment teeth therefore had a poor prognosis and were lost and/or extracted.

A recent study found out that the use of FSD had a direct detrimental effect on the health of abutment tooth and cause alveolar bone resorption. Bone loss between the abutment tooth and adjacent tooth were also compared and results showed that bone loss in abutment tooth was statistically more significant $(p<0.05)$ compared to the adjacent tooth which indicates the direct impact of fixed self-cure dentures on alveolar bone. These results correlate with the findings of our study which showed that a total of $64 \%$ abutments were having bone resorption leading to mobility.

The prosthesis itself were mostly worn out and discolored due to loss of color stains and a low abrasion resistance characteristic of self-cured resins, leading to poor esthetics and inefficient mastication. $37.3 \%$ FSD were found fractured under opposing occlusal forces due to low tensile strength of auto polymerizing acrylic resins.

\section{SUGGESTIONS}

The patients must be educated about increase in frequency of malpractices carried out in dentistry including maltreatment with fixed self-cured acrylic dentures which can lead to a plethora of serious complications. The patients should be encouraged for regular dental visits so that preventive measures can be carried out and a general awareness may be created regarding standardized treatment options available in scenarios of missing teeth.

Permanent actions should be taken against quack that prey on poor uneducated masses and so casually put the peoples' oral health in jeopardy. Severe restrictions should also be enforced on so called 'qualified dentists' propagating these maltreatments to save time and cut treatment costs, defrauding patients by providing self-cure acrylic dentures in name of fixed prosthesis.

Patients should be educated about Removable Cast partial dentures as valid treatment options especially in cases where fixed prosthesis is not recommended. The notion of removable prosthesis as being inferior to a fixed option should be destigmatized. Stable cast RPDs should be planned and made where recommended to provide patients with good affordable treatment alternative to FPD and implants.

\section{CONCLUSION}

According to this study, it was observed that patients' lack of awareness was the main reason for opting FSD. The most common presenting complaint was pain, followed by poor esthetics. The prevalent clinical complications included poor oral hygiene, halitosis, burning mouth together with inflamed and ulcerative mucosa and, mobile and carious abutments. Prosthesis related complications included poor denture hygiene, wore out and fractured prosthesis with discoloration. An awareness on the complications of such maltreatment among patients is required to be created in order to discourage this malpractice.

Copyright@ 20 Aug, 2019. 


\section{REFERENCES}

1. R. Gautam, "Biocompatibility of polymethylmethacrylate resins used in dentistry," Journal of Biomedical Materials Research Part B Applied Biomaterials, 2012.

2. S. Kohli, "Discolouration of polymethyl methacrylate versus acrylic based provisional crown and bridge dental resins: Effect of storage media and duration," Annals of Medical and Health Sciences Research, 2017.

3. H. Rashid, Z. Sheikh and V. Fahim, "Allergic effects of the residual monomer used in denture base acrylic resins," European Journal of Dentistry, p. 614, 2015.

4. A. Bettencourt, "Biodegradation of acrylic based resins; A review," Dental Materials, 2015.

5. Stoeval, "The oral tolerance to contact allergens in prosthodontic biomaterials," Journal of IMAB, 2010.

6. S. Hagberg, G. Ljungkvist and H. Andreasson, "Exposure to volatile methacrylates in dental personnel," Journal of Occupational and Environmental hygiene, 2005.

7. C. d. V. Machado, "Effect of different curing condition on material properties of acrylic resin for orthodontic appliances," Orthodontic Waves, pp. 18-22, 2010.

8. J. H. e. a. Jorge, "Cytotoxicity of denture base acrylic resins: A literature review," The Journal of Prosthetic Dentistry, pp. 190-193, 2003.

9. A. Schedle, "Do adverse effects of dental materials exist? What are the consequences, and how can they be diagnosed and treated?," Clinical Oral Implants Research, 2017.

10. N. G. e. a. Pauly, "The curse of quackery in dentistry: A double-edged sword," Archives of Medicine and Health Sciences, p. 92, 2017.

11. H. Chauhan, "Is quackery still a parallel world of dentistry-A case report," Int J Oral Health Med Res, 2016.

12. K. N. Sushma and S. Kumar, "Fixed-removable partial denture-A case report," Indian Journal of Case Reports, pp. 249-251, 2017.
13. S. Puroshottam, "Quackery in dentistry-An uncurbed menace," International Journal of Contemporary Dentistry, 2013.

14. N. Azisa, N. Madihah and K. Zainol Abidin, "Acrylic partial dentures fixed to adjacent teeth: A case report on quack dentistry," Archives of Orofacial Sciences, 12015.

15. M. Kostic, "Adverse reactions to denture resin materials," European review for medical and pharmacological sciences, pp. 5298-5305, 2017.

16. D. Koutis, "Allergic contact stomatitis caused by acrylic monomer in a denture," Australasian Journal of Dermatology, 2010.

17. M. R. C. a. V. S. Syed, "Allergic reactions to dental materials-a systematic review," Journal of clinical and diagnostic research: JCDR, 2015.

18. S. Hahnel, "Performance of resin materials for temporary fixed denture prostheses," Journal of Oral Science, 2019.

19. H. Memon, "Assessment of patients wearing auto ploymerized acrylic resin fixed partial dentures," Pakistan Oral \& Dental Journal, March 2015.

20. S. Z. Mahmud, "Measurement of oral health literacy level among bangladeshi adults seeking dental care and its relationship with socio-demographic characteristics," Anwer Khan Modern Medical College Journal, pp. 34-39, 2016.

21. S. ,. S. T. A. B. Parlani, "A cross-sectional study to explore the reasons to visit a quack for prosthodontic solutions," The Journal of Indian Prosthodontic Society, 2018.

22. A. Jain, "Dental quackery in India: An insight on malpractices and measures to tackle them," British Dental Journal, p. 257, 20189.

23. R. H. a. A. N. Manoj Kumar Hans, "Quackery: A major loophole in dental practice in India," Journal of Clinical and Diagnostic Research: JCDR, p. 283, 2014.

24. S. Misra, L. Mishra, K. M and S. Niyogi, "Dental Malpractice, The Odds in Dental Treatment," Indian Journal of Public Health Research \& Development, pp. 2430-2434, 2018. 


\begin{tabular}{|c|c|c|c|}
\hline \multicolumn{4}{|c|}{ AUTHORSHIP AND CONTRIBUTION DECLARATION } \\
\hline Sr. \# & Author(s) Full Name & Contribution to the paper & Author(s) Signature \\
\hline 1 & $\begin{array}{l}\text { Maimuna Khokhar } \\
\text { Shabir Ahmed }\end{array}$ & $\begin{array}{l}\text { Idea, Introduction, } \\
\text { Methodology, Abstract. } \\
\text { Data collection. }\end{array}$ & $\frac{\text { Mecinnuna }}{230}$ \\
\hline 3 & Muhammad Ilyas Shaikh & Proof reading and analysis. & \\
\hline 4 & Safia Shaikh & $\begin{array}{l}\text { Conclusion and discussion } \\
\text { writing. }\end{array}$ & \\
\hline 5 & Bharat Kumar & Literature reveiw. & \\
\hline 6 & Muneeb Ahmed Lone & $\begin{array}{l}\text { Literature review and } \\
\text { referencing. }\end{array}$ & \\
\hline
\end{tabular}

